\title{
Analysis on the Path of the Innovation of the Cultural Quality-Oriented Education in University
}

\author{
Yanling Zhang \\ Northeast Petroleum University at Qinhuangdao, Qinhuangdao, China \\ Email: w ddan@163.com
}

Received 2 March 2015; accepted 17 March 2015; published 20 March 2015

Copyright (C) 2015 by author and Scientific Research Publishing Inc.

This work is licensed under the Creative Commons Attribution International License (CC BY). http://creativecommons.org/licenses/by/4.0/

(c) (i) Open Access

\section{Abstract}

We have proposed the concept of the cultural quality-oriented education for university in China, aiming at 'improving the students' aesthetic taste, cultural taste, humanistic quality and scientific quality through strengthening education on the subjects of literature, history, philosophy, arts and other humanities and social science and natural science in university". However, some colleges and universities tend to be utilitarian with knowledge-based and technique-based status in practice. They use the training mode of one-sided pursuit of employment, and neglect the development of the humanistic spirit. The curriculum is unable to adapt to the actual needs of students of different specialties, and the implementing effect of the cultural quality-oriented courses is below expectation. Only by surpassing this predicament can the cultural quality-oriented education in university be promoted on the inheritance and innovation fruitfully. Under the new situation, the specific path of the cultural quality-oriented education in university should be mainly paved in the curriculum setting, teaching management, learning selection and student evaluation.

\section{Keywords}

The Cultural Quality-Oriented Education in University, Innovation, Path

\section{Introduction}

Under the new situation, the cultural quality-oriented education in university still faces many new challenges and difficulties in China. A few colleges and universities tend to be utilitarian with knowledge-based and technique-based status in practice. They use the training mode of taking employment orientation, resulting that many colleges and universities have the one-sided pursuit of employment and neglect the cultivation of humanistic 
spirit and the development of innovation ability. Therefore, we need to study further, expand the current cultural quality-oriented education taking the education science, especially higher education science as theory support and footing, understand the cultural quality-oriented education from history and other subjects, and explore new mode of practice (Zhang, Q. Z., 2010).

The purpose of education is to cultivate all-round development of people. In ancient Greece, Athenians, at its free education that was created for the first time, pay attention to comprehensive and harmonious development of students. The ancient Greek philosopher, educator Socrates advocated the first to cultivate people's virtue, teach people to learn to behave, to become a virtuous man, then to teach people to learn from broad and practical knowledge. He thinks, the country must have a broad knowledge. From the German Humboldt to British Newman, from the USA Hutchins to Cole, they all thought of talents should be a man of culture, a harmonious personality, all-round development of the people, a wise and good man, a free generalist.

\section{The Connotation of the Cultural Quality-Oriented Education in Colleges and Universities}

The cultural quality-oriented education in university is a new thought and concept proposed according to the prevailing issue of valuing sciences and neglecting the humanities in Chinese higher education, the single mode of talent cultivation, the over-narrow and over-detail setting of major, the unbalance of student's knowledge structure and the lack of humanistic quality and etc. With culture as carrier, it is an education activity to improve the cultural quality of university students through the edification of personality, the development of humanistic spirit and the humanistic quality. It advocates the combination of scientific education and humanistic education. It promotes the development of humanistic quality in the cultivation of students' spirit of science and stresses the improvement of the scientific literacy in the enhancement of the humanistic spirit of students, and realizes the optimization of the knowledge structure and the improvement of the practice ability through perfecting personality and developing spiritual quality. Directed by the students' lifelong development, the cultural qualityoriented education in university creates good cultural atmosphere and develops the cultural activities to improve the students' overall quality, help and promote students to establish a reasonable knowledge structure and good thinking quality, finally making all-round talents out of students.

The school education is designed to cultivate all-round talents. Compared with modern university, the humanities education and science education are interwoven with each other in ancient Chinese higher education, with the pursuit of the idea of philosophy and the lofty value as basic purpose and spirit. Ancient people tried to shape people's personality and improve the people's mind through education (Zhang, D. L., 2010). Confucius in "The Analects of Confucius for Politics" said: "a man is not like a vessel”, which means that a gentleman should not only be used with one purpose just like a vessel but should have a wide adaptability; and he should do a good job in whatever he is engaged in.

In the 1990s, in order to solve the prevailing issue of valuing sciences and neglecting the humanities in Chinese higher education, the single mode of talent cultivation, the over-narrow and over-detail setting of major, the unbalance of student's knowledge structure and the lack of humanistic quality and etc., China proposed the concept of the cultural quality-oriented education for university, aiming at 'improving the students' aesthetic taste, cultural taste, humanistic quality and scientific quality through strengthening education on the subjects of literature, history, philosophy, art and other humanities and social science and natural science in university". Through more than ten years of hard work on theory innovation and practice exploration, the cultural qualityoriented education in university has win support among all people in Chinese colleges and universities.

\section{Rational Thinking on the Cultural Quality-Oriented Education of Colleges and Universities in China under the New Situation}

First of all, the cultural quality-oriented education in university under the new situation should be established on the basis of the existential philosophy which gives a new perspective for the cultivation of talents from university. In the view of existentialism, a good person is a man who works hard with a positive attitude to life. They have their own clear goals, and have the courage to realize their goals with down-to-earth work and positive attitude. From the aspect of the existential philosophy, "Living" is different from "being". "Being" refers to the existence of an individual, but may not bring any meaning; sometimes "existing individual" can be seen as nothing, because this individual has no influence on others; he/she hasn’t construct his/her own value. A "living” 
individual struggles actively, works hard to plan their meaning and could realize their goals and influence others. Compared with "being", we can also think that "living" is transcendental. On the basis of re-understanding on people from the aspect of the existential philosophy, the cultural quality-oriented education in university clears its oriented target: colleges and universities should cultivate students with the spirit of transcendence and quality.

Secondly, we should understand the cultural quality-oriented education in university comprehensively from the system theory under the new situation. The system theory emphasizes the complexity and the comprehensive thinking, which provides the cultural quality-oriented education in university with ideas and directions. In the cultural quality-oriented education, the university is regarded as a whole system. In this system, "non-equilibrium state is normal", and evolution is absolute, but stabilization is relative. In the inside and outside of the system, there are always games and conflicts in the curriculum setting, teaching management and logistics service and extracurricular activities; there are information exchange, collision and conflict all the time. The cultural quality-oriented education in university is oriented by the improvement and overall development of students' comprehensive quality, which tries to change the unhealthy tendency of "stressing sciences and neglecting humanities", "stressing knowledge and neglecting practice" and "stressing employment and neglecting quality", so as to balance the development of university and truly cultivate excellent talents for society.

Third, the cultural quality-oriented education in university under the new situation should attach great importance to promoting the development of students' non-intelligence factors, including emotion, will, interest, personality, motivation, needs, goals, ideals, beliefs, world outlook and etc. Non-intelligence factors are not directly involved in the cognitive activities, but directly restrict the cognitive process, and orient, maintain, promote, regulate and compensate the cognitive process. We attach great importance to promoting the development of students' non-intelligence factors in order to correct the current higher education with only one goal at imparting knowledge and training thinking ability, promote students to explore the development of spirit and encourage them to try and explore unknown fields. The spirit of exploration is an important factor indispensably to the development of innovative talent ( $\mathrm{Li} \& \mathrm{Yu}$, 2014). Csikszentmhalyi studied and found "the most notable feature of a creative individual is his/her persistent curiosity. They always have a new interest in things around them. The creative individual has the passion to pursue. Without such interest, a person may not concentrate on this major in depth, let alone change it”. The cultural quality-oriented education in university actively guide students to concern unknown fields outside their major, help them find pleasure in exploring and the truth in seeking, come up with new ideas and apply them in other aspects. Therefore, we should first explore the existing things, because only when we have the courage to explore and try, can we promote the formation of new thoughts, products and behaviors.

\section{The Specific Path of the Innovation on the Cultural Quality-Oriented Education of Colleges and Universities in China}

Under the new situation, the specific path of the cultural quality-oriented education in university should be mainly paved in the curriculum setting, teaching management, learning selection and student evaluation.

First of all, add public courses and professional courses in the curriculum setting. Through enriching public course's content or blending the content of public course into the professional courses, students could broaden their vision and expand their knowledge structure. They are no longer limited in their own professional major. In addition, expand the second classroom. We can create a link about extracurricular practice education attentively and explore implicit courses in order to broaden their learning channels and influence them in intangible and silent course (Qin, 2012). We can encourage students to organize societies by themselves, hold activities, and enrich their life through lectures, sports, religious activities, meetings, seminars, concerts and other forms of activities, to improve student's organization and management ability and develop their personality. These activities can develop students' ability to use knowledge, operation ability and self-consciousness to serve the society, which is required for the development of innovative talents. Appearing in the "informal" form, the second classroom and hidden courses are a remedy to the explicit education, which has broke the closed state of the traditional education, and made full use of existing forms in students' study and life. The cultural quality-oriented education in university could mobilize all levels of teaching elements, including teaching, service and management and etc., to influence people, and liberate education in time and space, which plays an important role in the promotion of cultural quality of students (Tian \& Mao, 2015). 
Secondly, introduce the concept of the interdisciplinary education in teaching management. With the comprehensiveness and pluralism of science, the interdisciplinary concept is becoming more and more important in the development of science. Some scholars have pointed out; the interdiscipline is the fruit of the close relationship and mutual effect of two or more subjects, ranging from simple academic thoughts, or even all-round exchange across academic viewpoints and methods, procedures, recognition and terminology and various kinds of data. "The interdisciplinary education introduces the interdisciplinary thought into education activities, so as to create a new type of education form for cultivating interdisciplinary talents. The interdisciplinary education integrates teaching into and research, making it with more research-oriented education color. The personnel with the interdisciplinary education are interdisciplinary talents. They have more extensive knowledge, more reasonable structure, stronger adaptability, greater possibility of innovation and creation.” Under the new situation, the cultural quality-oriented education in university requires colleges and universities to break limit of schools, faculties and departments, providing more convenience for students to select course.

Third, give more respect to students on their selection of course. In order to meet the actual needs of students in study, many developed countries have set required modules, and at the same time they respect students on their selection. For example, American colleges and universities adopt the popular credit system, for it gives students right to select courses. Every student can select suitable courses combined with their ability, study level and interest (Zhou, 2011). At Harvard University, students can even create a new specialty according to their market survey and prediction after recognized and approved the academic committee of the school. The teaching system enables students to study independently and purposely, broad their thought and develop a good practical ability. However, it has a higher requirement for students' independent course-selecting level and teachers' teaching ability.

Fourth, insist on the formative evaluation in the evaluation of students. Under the new situation, the evaluation objective of the cultural quality-oriented education in university is to promote the improvement of students' cultural quality. The cultural quality-oriented education of university advocates a qualitative evaluation rather than a non-quantitative evaluation. It mainly uses descriptive words to distinguish students' progress. This evaluation method helps students change their competitive tendencies, so that they no longer compete or compare on score, contest level and award rating. They can look at their progress objectively with their past status as the reference, so as to form good belief, personality, intelligence and emotion and morality, ability and other qualities, improve quality and develop creativity. Therefore, maximize the use of the method of formative evaluation. The formative evaluation evaluates the whole development process of the students, aiming at confirming the students' potential and improving the mode of development. In the cultural quality-oriented education in university, it is suggested to use the formative evaluation to evaluation the results students obtained in the progress of their cultural quality, for it can reflect students' emotion, attitude, strategy, encourage students to improve their cultural quality constantly, help students to effectively control the promoting process of their cultural quality, enable students to obtain a sense of achievement, and enhance their self confidence (Guo, 2014).

The cultural quality-oriented education in university is "an advanced education idea" in Chinese higher education. In the past, we have paid a price for the development of higher education, also made the world recognized achievements in different period, now is a good summary of research and exploration when the ideological system of higher education Chinese characteristics, and of which the cultural quality education as the breakthrough point of quality education to have Chinese characteristics of higher education thought, is an important educational thought embodied education policy. Under the new situation, it is the requirement for higher education to carry out the cultural quality-oriented education with the continuous progress of the society, and reflects the new development of the higher education theory and practice. It will play a positive role in further implementing the cultural quality-oriented education in university, emphasizing scientific system construction, forming a strong academic atmosphere, carrying out teaching reform, holding rich cultural activities, forming a good campus environment, and cultivating the unique university spirit.

\section{References}

Guo, X. L. (2014). Overview of University Culture Research. Journal of Henan Institute of Education, 6.

Li, X. B., \& Yu, Y. (2014). The Inheritance and Innovation of Culture Quality Education in University. Journal of Hebei Normal University, 1.

Qin, J. Y. (2012). Enlightenment on the Cultural Quality-Oriented Education of College Students in China from Interdiscip- 
linary Education of American University. Journal of Heilongjiang Institute of Education, 11.

Tian, L. J., \& Mao, R. (2015). Normal form of Integrative Research on University Culture. Social Science Forum, 1.

Zhang, D. L. (2010). Perseverance in the Development of Cultural Quality-Oriented Education in Universities. Chinese Higher Education Research, 7.

Zhang, Q. Z. (2010). Discussion on the Culture Quality-Oriented Education in University from an Advanced Education Idea. Chinese Higher Education Research, 10.

Zhou, Y. Q. (2011). Quality-Oriented Education-An Education Thought Reflecting Chinese Education Policy. Chinese Higher Education Research, 9. 